\title{
The quality of environmental planning in the assessment of residents of Moscow
}

\author{
Igor' Pryadko ${ }^{1, *}$ \\ ${ }^{1}$ Moscow State University of Civil Engineering, 26, Yaroslavskoe shosse, 129337, Moscow, Russia
}

\begin{abstract}
The paper analyzes the results of a sociological survey conducted in February-March 2020 by teachers and students of NRU MSUCE on the topic "Urboecological planning and design in the assessment of the young generation of townspeople." The survey was conducted among young people permanently residing in the metropolitan area, including in the territory of New Moscow. The study identified the main challenges and problems facing city authorities and civil society in the in the metropolitan area and Moscow region. Some measures of urban ecological planning and design are considered. The author analyzes the components of the ecological culture of the townspeople, in the structure of which he distinguishes ecological education, ecological upbringing and ecological behavior. The results of the study can be used in planning and conducting environmental protection measures both in large metropolitan areas, in particular in Moscow, and in medium-sized settlements.
\end{abstract}

\section{Introduction}

The concentration of pollutants in urbanized areas is a topic that is quite often raised by both representatives of the expert community and opinion leaders (see $[1,2,3,4,5]$ ). Attention is paid to the medical and environmental aspects of the problem [6]. The issues of creating a comfortable, biosphere-compatible space in cities are decided by specialists in the field of urban ecology. This science in the last decade of the XX century has become an independent system of scientific knowledge. Particularly acute is the problem of environmental protection, the problem of cleaning geospheric shells from pollutants is faced not only by the authorities of megacities, but also by the civil society of large settlements. Environmental activities that require large financial costs are also carried out in the region of the Russian capital.

Cities are not only material objects, but also ordered structures of social relations [7, 8]. The system of cities includes territories, geological environment, soils, surface and underground waters, surface layers of the atmosphere - all these are abiotic components of the biosphere that actively interact with urban structures [9]. The scale of the impact of cities on these structures can hardly be overestimated. A city is also its population, a complex system of social relations, the movement of finances, which provides economic, business, social and environmental activities of urban structures. Maintaining the balance of these components is not only a social task, but also an economic one.

\footnotetext{
* Corresponding author: priadcko.igor2011@yandex.ru
} 
In the developed countries of the world, measures to preserve the urban environment, utilize municipal solid waste (MSW), control the cleanliness of the urban atmosphere, soil, and water bodies within cities are generously funded, and a budget is allocated for urban environmental planning and design. And in our country, environmental policy is implemented at the legislative, executive and judicial levels of political power, as well as at the federal, regional and municipal levels.

Familiarity with the findings of urban ecology is necessary not only for the community of experts, not only for civil society, but also for financiers, since it is necessary to plan a budget for measures to protect the environment. For environmental activities to be funded, civil society must be aware of their need. However, the knowledge of modern townspeople about nature, about its connection with society is fragmentary. The average city dweller is hardly able to determine how the natural environment changes in the course of human production activities. He hardly knows how the interaction takes place in the "society nature - human" system. Even fewer people are able to assess the economic damage from environmental emergencies. In this regard, it is difficult to disagree with the thesis that environmental degradation is a consequence of the spiritual and ideological crisis in society. The ideology of consumption, which has become widespread in the last decades of the XX century all over the world, does not meet the urgent requirements of the development of human society, but leads to its spiritual and physical destruction, including as a result of natural and man-made disasters, environmental pollution and depletion of natural resources.

In order to overcome the consumption mindset prevailing over many people, it is necessary to pay attention to three aspects of economic culture: environmental education associated with the dissemination of information about the environmental challenges of modern civilization; environmental upbringing, which is based on respect for the human environment; ecological behavior, which includes a system of measures and actions for nature protection and nature management.

\section{Materials and Methods}

The survey was conducted by teachers and students of the EMIS Institute of the NRU MSUCE on the topic "Urboecological planning design in the assessment of the young generation of townspeople". The survey was dedicated to the goals of environmental education and was conducted in January-February 2020. 152 residents of Moscow took part in the survey, most of whom were students and applicants from a number of Moscow universities. When asked about social status, the majority answered: "university student", "study and work", "schoolchild", etc. (see diagram 1 in Fig. 1). 


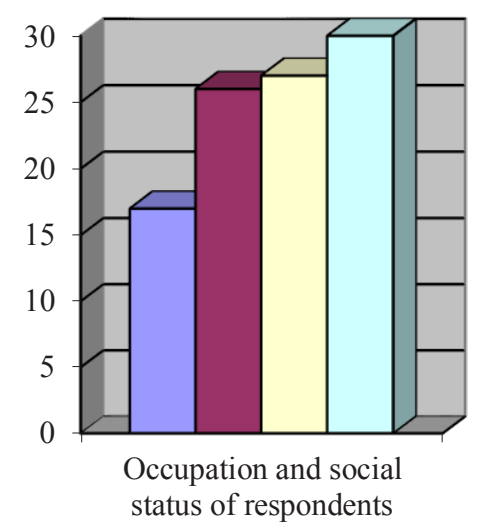

$\square$ Studying in secondary school

$\square$ Studied in high school

$\square$ Work at enterprises

$\square$ Combine work and study

Fig. 1. Occupation of respondents.

Social and demographic characteristics of the respondents included in the sample are presented in the following diagrams (see Fig. 2, 3).

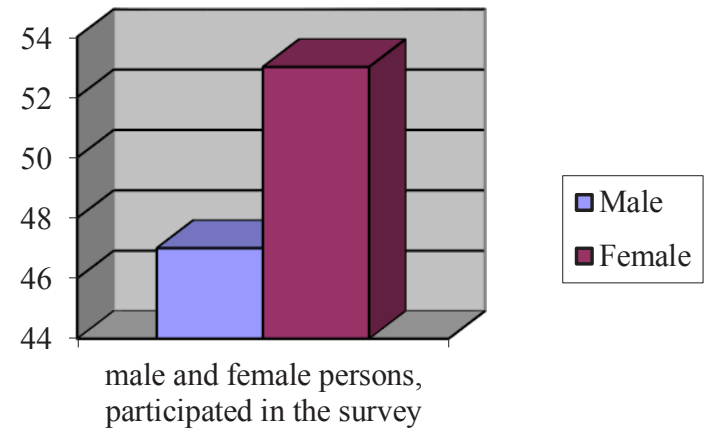

Fig. 2. The ratio of men and women who participated in the survey.

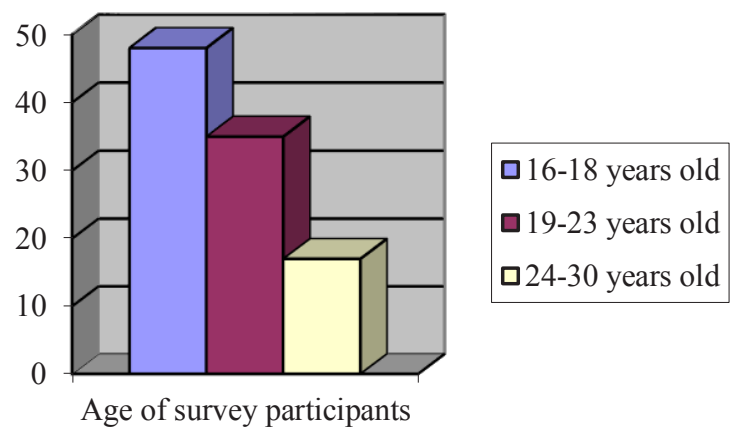

Fig. 3. Age of survey participants. The diagram shows that the surveyed audience was young.

A personalized individual questionnaire, which was distributed to the respondents, was used as a tool for collecting the information necessary for the study [10]. The answers of the respondents will be presented and interpreted in the following paragraphs of this paper. 


\section{Results}

When asked about the importance of urban environmental planning and design for a modern city, the overwhelming majority of respondents $(89 \%)$ answered that this area of planning is extremely important, and only $4 \%$ of the respondents considered the issues of urban environmental planning and design to be secondary. $6 \%$ of the respondents found it difficult to answer, and $1 \%$ of the respondents proposed their own formulation of the answer (for example, "there is no problem of urban ecological planning, but there is a problem of poorly educated citizens, their environmental upbringing", "depends on a particular city", etc.) (see Fig. 4).

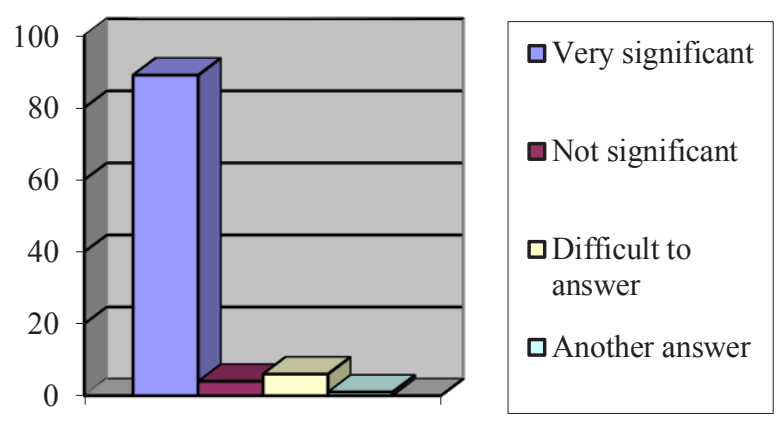

Fig. 4. Distribution of answers to the question: "How important are urban ecological planning and design for the life support of modern megacities?".

On the basis of the above, it can be argued that the problems of protecting the urban environment are understood by the society, and the respondents are well aware of these problems. In doing so, they can outline the range of activities required to create a biosphere-compatible urban environment. But at least some of the tasks of environmental education in the framework of educational events held in higher education are being solved, although the goals of environmental propaganda remain unattained.

Respondents' answers to the question: "How do you assess the ecological situation in your settlement?" show how concerned civil society is about environmental pollution in cities. More than half of the respondents called the situation in the cities critical. Another $37 \%$ of the survey participants, believing that the situation in the metropolitan area is favorable, indicated the presence of a number of unsolved problems. Only $4 \%$ of respondents assessed the situation in the city as fully favorable (Fig. 5). 


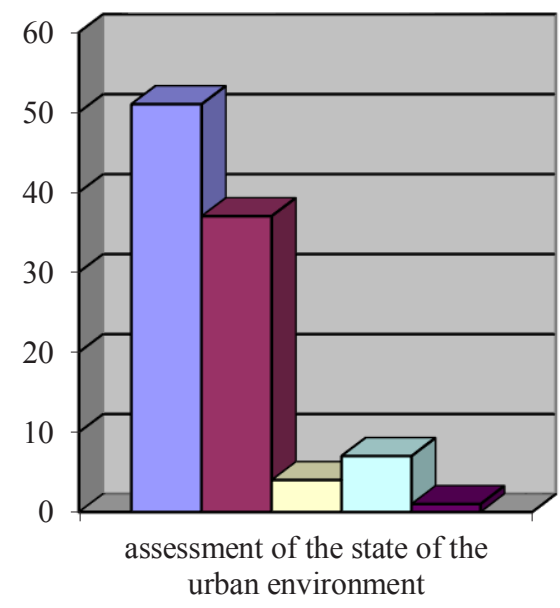

$\square$ Keeping the environment in the city close to the critical.

$\square$ The stopping of the medium in the city reverses the tree

$\square$ The service of the city environment is good.

$\square$ Difficult to answer

offered their own answer

Fig. 5. Assessment of the state of the urban environment by residents of the megalopolis.

The thesis sounds quite banal that those streets and squares of the city, where they do not litter, remain clean. In this regard, it is of interest how the respondents act if it is necessary to throw out garbage, and there are no trash cans nearby. Despite the high deficit of trash cans in the city, most of the respondents try not to throw garbage directly on the ground or asphalt (paving slabs). This was the answer of $65 \%$ of the respondents. In some cases, $26 \%$ do it, and 5\% admitted that they throw small rubbish on the ground (on the floor) in exceptional cases. 3\% of the respondents answered that they throw out small rubbish on a regular basis, and $1 \%$ of the survey participants found it difficult to answer or offered their own version (the question was half-closed).

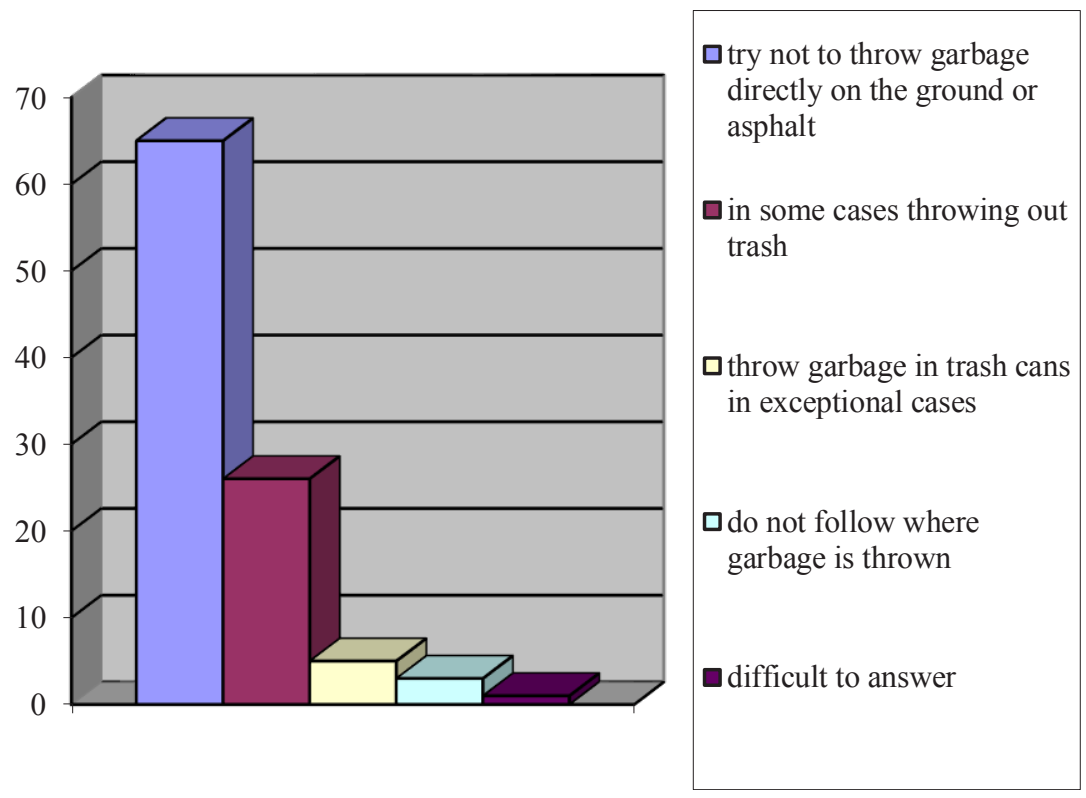

Fig. 6. Contribution of respondents to cleaning city streets from garbage. 


\section{Discussion}

One question in the questionnaire asked the respondents to rank the factors influencing the state of the urban environment. In the first place, the survey participants put the air pollution in cities. The opinion of the respondents coincided with the conclusions made by the representatives of the scientific community. To monitor the state of atmospheric air, specialists in the field of urban ecology have developed special standards - maximum permissible concentrations. Such standards are established for carbon oxide and monoxide, sulfur compounds, nitrogen oxides, volatile hydrocarbons and other pollutants. At rush hour in the center of a large megacity, the concentration of carbon dioxide can exceed the permissible level by 50 times, nitrogen oxides - 150 times, volatile hydrocarbons - up to 1.5-2 thousand times. A photo-chemical fog called smog is forming.

It is extremely important to maintain the gas balance of the atmosphere. And for this it is necessary to purchase filtering equipment, to improve technological processes in production. For a comfortable life of humanity inhabiting the planet, it is enough to enter the atmosphere of 800 million tons of oxygen per year. The accumulation of oxygen in the atmosphere significantly exceeds this volume. On the other hand, industrial production and transport, concentrated in cities, annually consume 10-12 billion tons of this gas necessary for life, and such a high level of consumption is the reason for the disruption of the gas balance of the atmosphere. The preservation of the existing state of affairs should lead to a change in the composition of the Earth's atmosphere in 100-150 years [4, p. 61]. However, the funds allocated by enterprises for air recovery are insufficient.

The second in the ranking among the respondents is the problem of pollution of the hydrosphere within megacities [11]. Watercourses and reservoirs here are threatened by wastewater, the volume of which increases with the growth of the population of megacities, rapid urbanization, the development of urban industry and transport systems. Every year the volume of polluted water on Earth increases by $5000 \mathrm{~km}^{3}$ [9] (see also [12]). In general, the concerns of the survey participants in relation to the state of the urban hydrosphere are fully justified.

Removal of solid waste and garbage collection is ranked by the respondents in third place $[13,14]$, and the problem of environmental upbringing took the fourth place. The respondents express regret that the majority of urban dwellers do not yet take part in environmental protection activities (Fig. 7). The rest of the problems of urban ecology were selected by a smaller number of respondents. Let us recall that this is the opinion of the representatives of the most active part of the townspeople - young people studying in institutions of secondary and higher education of Moscow. 

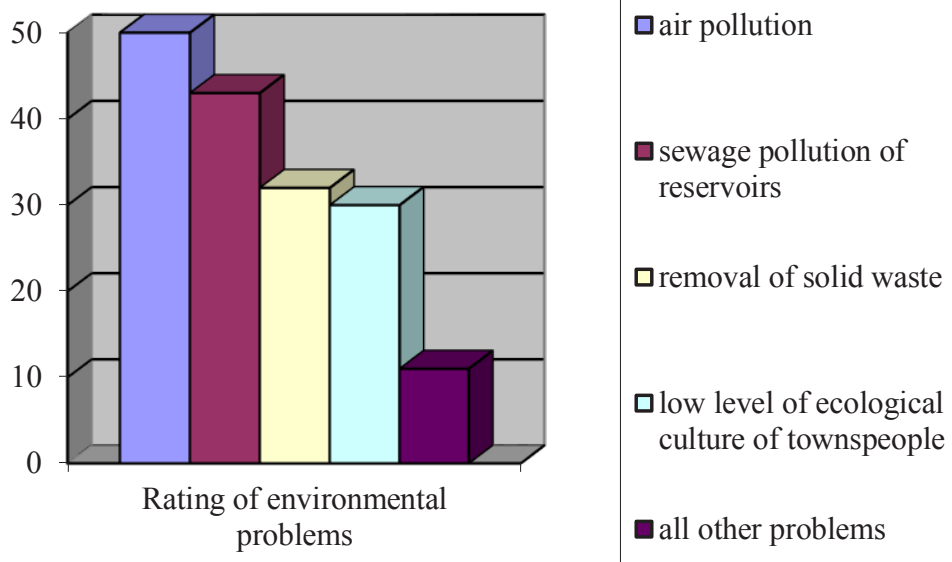

Fig. 7. Rating of environmental problems and threats.

Of interest are the responses of the survey participants to the question: "Who is responsible for the state of the environment in a megacity?" Most of the respondents assigned this responsibility to all participants in social interaction in cities: to civil society, motorists and pedestrians, municipal authorities, experts, etc. This, according to the convictions of the respondents, is evidence that programs are needed that involve a wide range of the population in environmental activities (see [15]).

The majority of the respondents also believe that the condition for preserving the urban environment in the metropolitan area is the creation of new green areas, planting trees and planting flower beds, renewing existing green spaces, as well as reconstruction of enterprises and treatment facilities. Measures that are local in scope will have an impact on the overall situation in the city. After all, a big business begins with small things.

\section{Conclusions}

Based on the analysis of the results of the study, the author of the paper concluded that the hypothesis put forward at the beginning of the survey was partially confirmed. Despite a good awareness of the problems associated with the need to maintain a balance of the natural environment, most of the respondents are not ready to give up the comfort that the urban technological environment provides them.

In the course of the study, it was found that the state of the urban atmosphere, the growth of pollution by wastewater and industrial waste of water bodies located within megacities, and the growing volume of solid waste, poisoning the biota in urbanized territories, are of particular concern to young residents of the megacity. Among the problems associated with environmental education and upbringing, the respondents who participated in the survey noted a low level of awareness among townspeople themselves in issues of urban environmental planning and design. However, people in general are ready to put things in order in their city. The use of reusable bags and waste sorting are viewed by the respondents as a private measure to achieve the main goal of creating a biospherecompatible, clean space in cities.

It is obvious that in the near future it is necessary to resolve the problems listed by the respondents as soon as possible. These problems continue to remain complex and ambiguous. After all, each member of the urban community needs to provide conditions for 
decent living in such a way that both human and nature feel equally comfortable, and it would be possible to continue further human living on the planet, which is gradually becoming an "urban-type planet" $[15,16,17,18]$.

\section{References}

1. V. Bogolyubov, Modern scientific research and their practical application 11408(6), 25 (2014)

2. S. Kurolap, O. Klepikov, P. Vinogradov, V. Gritsenko, Baltic Region 8(4), 108 (2016) DOI: $10.5922 / 2079-8555-2016-4-10$

3. S. Litvinov, A. Kogan, International Journal of Applied Engineering Research 11, 9894 (2016)

4. S. Mudrak, I. Pryadko, Journal of Economy and entrepreneurship (to be published)

5. I. Pryadko, Urbanism 2, 38 (2017) DOI: 10.7256/2310-8673.2017.2.23036

6. E. Godina, I. Khomyakova, A. Purundjan, L. Zadorozhnaya, A. Stepanova, Journal of Physiological Anthropology and Applied Human Science 24, 313(2005)

7. A. Boltaevsky, Vestnik Moscow City University 4, 97 (2015)

8. A. Mottaeva, MATEC Web of Conferences $\mathbf{0 7 0 2 0}$ (2016) DOI: $10.1051 /$ matecconf $/ 20167307020$

9. V. Vladimirov, Urboecology (FGBOU VPO «MNEPU», Moscow, 1999)

10. A. Boltaevsky, I. Andreev, Sociology (MSUCE, Moscow, 2013)

11. V. Kuprianov, Hydrological aspects of urbanization (LSU, Leningrad, 1977)

12. A. Mottaeva, A. Ivashchenko, A. Ryattel, E3S Web of Conferences 164, 10038 (2020) https://doi.org/10.1051/e3sconf /202016410038

13. I. Kozina, Problems of innovative biosphere-compatible, social and economic development in the construction, housing and communal and road complexes (FGBOU VPO «BGITU», Bryansk, 2015)

14. A. Mottaeva, J. Ćetković, Advances in Intelligent Systems and Computing 692, 1151 (2017)

15. A. Boltaevsky, I. Pryadko, Sociodynamics 3, 1 (2016) DOI: 10.7256/24097144.2016.3.18043

16. N. Tulebayeva, D. Yergobek, G. Pestunova, A.Mottaeva, Z. Sapakova, E3S Web of Conferences 159, 01012 (2020) https://doi.org/10.1051/e3sconf/202015901012

17. A. Mottaeva, A. Zheltenkov, E3S Web of Conferences 01038 (2018)

18. Z.I. Ivanova, N.V. Danilina, M.A. Slepnev, E3S Web of Conferences 91, 05012 (2019) DOI: https://doi.org/10.1051/e3sconf /2019910 